\title{
Colon Cell Image Segmentation based on Level Set and Kernel-Based Fuzzy Clustering
}

\author{
Amin Gharipour, Alan Wee-Chung Liew \\ School of Information and Communication Technology \\ Gold Coast campus, Griffith University, QLD4222, Australia \\ amin.gharipour@griffithuni.edu.au, a.liew@griffith.edu.au
}

\begin{abstract}
This paper presents an integration framework for image segmentation. The proposed method is based on Fuzzy c-means clustering (FCM) and level set method. In this framework, firstly Chan and Vese's level set method (CV) and Bayes classifier based on mixture of density models are utilized to find a prior membership value for each pixel. Then, a supervised kernel based fuzzy c-means clustering (SKFCM) algorithm assisted by prior membership values is developed for final segmentation.

The performance of our approach has been evaluated using high-throughput fluorescence microscopy colon cancer cell images, which are commonly used for the study of many normal and neoplastic procedures. The experimental results show the superiority of the proposed clustering algorithm in comparison with several existing techniques.
\end{abstract}

Keywords: Image segmentation; fuzzy c-means; kernel based fuzzy cmeans; supervised kernel based fuzzy c-means; Chan-Vese method; Bayes classifier

\section{Introduction}

In recent years, although different methods for the segmentation of cell nuclei in fluorescence microscopy images have been proposed, it is still considered as one of the critical but challenging tasks in the analysis of the function of cell in fluorescence microscopy images. Typically, image segmentation techniques based on fuzzy clustering and level set methods are two important techniques utilized for segmenting images into different non-overlapping, constituent regions. Whereas level set methods impose constraints on boundary smoothness, fuzzy clustering segmentation is based on spectral characteristics of individual pixel.

The level set technique for image segmentation was initially proposed by Osher and Sethian [1]. Based on the idea of Osher and Sethian, Malladi et al. [2] suggested a front-propagation method for shape modeling. Later, Chan and Vese [3] proposed CV method using an energy minimization technique and incorporated region-based information in the energy functional as an extra constraint. The basic idea behind their method was to look for a specific partition of an image into two parts, one character- 
izing the objects to be identified, and the second one characterizing the background. The active contour was represented by the boundary among these two parts.

As a powerful data clustering algorithm, FCM $[4,5]$ reveals the original structure of the image data and classifies pixels into clusters based on a similarity measure. This allows a segmentation of groups of pixels into homogenous region during image segmentation $[6,7,8]$. This clustering is acquired by iterative minimization of a cost function that is influenced by the Euclidean distance of the pixels to the cluster prototypes. One of the disadvantages of FCM is that Euclidean distance can only be used to detect 'spherical' clusters. To overcome this drawback, many modified FCM algorithms based on the kernel methods (KFCM) have been suggested to handle nonspherical clusters [9].

Whereas CV method focuses on geometrical continuity of segmentation boundaries, FCM aims to analyze spectral properties of image pixels and does not consider topological information. Since level set method and FCM use different types of information, it is possible that they yield different segmentation results. Nevertheless, the topological information captured in the CV method and the pixel's spectral properties captured by FCM are complementary in nature and consider them together would improve the segmentation result. Hence, an integration strategy is employed in this work to use the rich information offered by both methods. The main contribution of this paper is the introduction of an integration framework for KFCM and CV. The performance improvement compared to some well-known techniques using cell images is reported.

The organization of this paper is as follows. Firstly, a brief overview of CV level set based approach and FCM is given. Next, the proposed integration procedure is addressed in detail. Experiments are then discussed in Section 4. Finally, Section 5 concludes the paper and highlights possible future work.

\section{Previous works}

\subsection{Chan-Vese model}

Let $\Omega$ denotes the image domain, $\mathrm{C} \subset \Omega$ denotes the smooth, closed segmenting curve, $\mathrm{I}_{0}: \Omega \rightarrow \mathrm{R}$ is a given image, I denotes the piecewise smooth estimation of $I_{0}$ with discontinuities among $C,|C|$ denotes the length of C. $\mu$ and $v$ denote constant with positive values. The general form for the Mumford-Shah energy functional can be written as follows:

$$
\mathrm{E}^{\mathrm{MS}}(\mathrm{I}, \mathrm{C})=\int_{\Omega}\left|\mathrm{I}_{0}(\mathrm{x}, \mathrm{y})-\mathrm{I}(\mathrm{x}, \mathrm{y})\right|^{2} \mathrm{dxdy}+\mu \int_{\Omega \mathrm{C} C}|\nabla \mathrm{I}(\mathrm{x}, \mathrm{y})|^{2} \mathrm{dxdy}+\mathrm{v} \cdot|\mathrm{C}|
$$

The CV method solves (1) through minimizing the following energy functional:

$$
\mathrm{E}^{\mathrm{CV}}\left(\mathrm{c}_{1}, \mathrm{c}_{2}, \mathrm{C}\right)=\lambda_{1} \cdot \int_{\text {inside(c) }}\left|\mathrm{I}_{0}(\mathrm{x}, \mathrm{y})-\mathrm{c}_{1}\right|^{2} \mathrm{dxdy}+\lambda_{2} \cdot \int_{\text {outside(C) }}\left|\mathrm{I}_{0}(\mathrm{x}, \mathrm{y})-\mathrm{c}_{2}\right|^{2} \mathrm{dxdy}+|\mathrm{C}|
$$


where $\lambda_{1}, \lambda_{2}$ and $\mu$ denote positive constants. $c_{1}, c_{2}$ are the intensity averages of $\mathrm{I}_{0}$ inside $\mathrm{C}$ and outside $\mathrm{C}$.

In the $\mathrm{CV}$ method, the level set method which replaces the unknown curve $\mathrm{C}$ by the level set function $\varnothing(\mathrm{x}, \mathrm{y})$ is utilized to minimize (2). Therefore (2) can be reformulated in terms of level set function $\varnothing(\mathrm{x}, \mathrm{y})$ as follows:

$\mathrm{E}^{\mathrm{CV}}\left(\mathrm{c}_{1}, \mathrm{c}_{2}, \varnothing(\mathrm{x}, \mathrm{y})\right)=$

$\lambda_{1} \cdot \int_{\Omega}\left|I_{0}(x, y)-c_{1}\right|^{2} H_{\varepsilon}(\varnothing(x, y)) d x d y+\lambda_{2} \cdot \int_{\Omega}\left|I_{0}(x, y)-c_{2}\right|^{2}\left(1-H_{\varepsilon}(\varnothing(x, y)) d x d y\right.$

$+\mu . \int_{\Omega} \delta_{\varepsilon}(\varnothing(\mathrm{x}, \mathrm{y}))|\nabla \varnothing(\mathrm{x}, \mathrm{y})| \mathrm{dxdy}$

where $\mathrm{H}_{\varepsilon}(\mathrm{z})$ and $\delta_{\varepsilon}(\mathrm{z})$ denote the regularized versions of the Heaviside function $H(z)$ and $\delta(z)$ specified by $H(z)=\left\{\begin{array}{l}1 \text { if } z \geq 0 \\ 0 \text { if } z \leq 0\end{array}\right.$ and $\delta(z)=\frac{\partial H(z)}{\partial z}$, respectively.

The existence of minimizer for (3) has been considered in [10,11]. Using EulerLagrange method, the level set equation for evolution procedure is given by:

$$
\frac{\partial \emptyset}{\partial \mathrm{t}}=\delta_{\varepsilon}(\varnothing)\left[\mu \operatorname{div}\left(\frac{\nabla \varnothing}{|\nabla \varnothing|}\right)-\lambda_{1}\left(\mathrm{I}_{0}-\mathrm{c}_{1}\right)^{2}+\lambda_{2}\left(\mathrm{I}_{0}-\mathrm{c}_{2}\right)^{2}\right]
$$

where $\mathrm{c}_{1}$ and $\mathrm{c}_{2}$ can be, respectively, updated as follows:

$\mathrm{c}_{1}(\varnothing)=\frac{\int_{\Omega} \mathrm{I}_{0}(\mathrm{x}, \mathrm{y}) \mathrm{H}_{\varepsilon}(\varnothing(\mathrm{x}, \mathrm{y})) \mathrm{dxdy}}{\int_{\Omega} \mathrm{H}_{\varepsilon}(\varnothing(\mathrm{x}, \mathrm{y})) \mathrm{dxdy}} \mathrm{c}_{2}(\varnothing)=\frac{\int_{\Omega} \mathrm{I}_{0}(\mathrm{x}, \mathrm{y})\left(1-\mathrm{H}_{\varepsilon}(\varnothing(\mathrm{x}, \mathrm{y}))\right) \mathrm{dxdy}}{\int_{\Omega}\left(1-\mathrm{H}_{\varepsilon}(\varnothing(\mathrm{x}, \mathrm{y}))\right) \mathrm{dxdy}}$

\subsection{Kernel-based fuzzy c-means clustering algorithm}

The FCM algorithm, as a variation of the standard k-means clustering, was first proposed by Dunn [4], and further developed by Bezdek [5]. FCM aims to partition $\xi=\left(\xi_{1}, \ldots, \xi_{\text {n }}\right)$ i.e., a set of voxel or pixel locations in $\Omega$ into $\eta$ clusters, that are defined by prototypes $\mathrm{V}=\left(\mathrm{v}_{1}, \ldots, \mathrm{v}_{\eta}\right)$. With fuzzy clustering, each $\xi_{\mathrm{j}}$ is a member of all partitions simultaneously, but with different membership grades. The FCM algorithm achieves the final solution by solving:

Minimize $J_{\mathrm{FCM}}(\mathrm{U}, \mathrm{V})=\sum_{\mathrm{i}=1}^{\eta} \sum_{\mathrm{j}=1}^{\mathrm{n}} \mathrm{u}_{\mathrm{ij}}^{\mathrm{m}}\left\|\xi_{\mathrm{j}}-\mathrm{v}_{\mathrm{i}}^{2}\right\|^{2}$

subject to $\mathrm{U} \in \mathrm{M}, \mathrm{m} \in[1, \infty]$, 
Where $\mathrm{M}=\left\{\mathrm{U}=\left[\mathrm{u}_{\mathrm{ij}}\right]_{\mathrm{i}=1, \ldots, n} \mid \mathrm{u}_{\mathrm{ij}} \in\left[0, \ldots, \mathrm{n} \mid \mathrm{n}, \sum_{\mathrm{i}=1}^{\eta} \mathrm{u}_{\mathrm{ij}}=1\right\}\right.$

The parameter $m$ affects the fuzziness of the clusters. As can be seen from (6) every pixel has the same weight in the image's data set. Fuzzy clustering under constraint (6) is called probabilistic clustering and $\mathrm{u}_{\mathrm{ij}}$ is the posterior probability $p\left(\eta_{i} \mid \xi_{j}\right)[12]$. Alternating optimization, which alternates between optimizations of $\tilde{\mathrm{J}}_{\mathrm{FCM}}(\mathrm{U} \mid \dot{\mathrm{V}})$ over $\mathrm{U}$ with fixed $\dot{\mathrm{V}}$ and $\tilde{\mathrm{J}}_{\mathrm{FCM}}(\mathrm{v} \mid \dot{\mathrm{U}})$ over $\mathrm{v}$ with fixed $\mathrm{U}$ converges to a local minimizer or a saddle point of $\mathrm{J}_{\mathrm{FCM}}[13]$.

Now we replace the Euclidean distance in (6) by the distance function $\left\|\Theta\left(\xi_{j}\right)-\Theta\left(v_{i}\right)\right\|^{2}$ where $\Theta$ denotes a map on feature space. Therefore (6) can be rewritten as follows:

$$
\mathrm{J}_{\mathrm{KFCM}}(\mathrm{U}, \mathrm{V})=\sum_{\mathrm{i}=1}^{2} \sum_{\mathrm{j}=1}^{\mathrm{n}} \mathrm{u}_{\mathrm{ij}}^{\mathrm{m}}\left\|\Theta\left(\xi_{\mathrm{j}}\right)-\Theta\left(\mathrm{v}_{\mathrm{i}}\right)\right\|^{2}
$$

In terms of inner product, the distance function can be expressed as follows:

$$
\left\|\Theta\left(\xi_{\mathrm{j}}\right)-\Theta\left(\mathrm{v}_{\mathrm{i}}\right)\right\|^{2}=<\Theta\left(\xi_{\mathrm{j}}\right), \Theta\left(\xi_{\mathrm{j}}\right)>-2<\Theta\left(\xi_{\mathrm{j}}\right), \Theta\left(\mathrm{v}_{\mathrm{i}}\right)>+<\Theta\left(\mathrm{v}_{\mathrm{i}}\right), \Theta\left(\mathrm{v}_{\mathrm{i}}\right)>
$$

We set $<\Theta\left(\xi_{\mathrm{j}}\right), \Theta\left(\mathrm{v}_{\mathrm{i}}\right)>=\mathrm{K}\left(\xi_{\mathrm{j}}, \mathrm{v}_{\mathrm{i}}\right)$. Hence (8) can be formulated as follows:

$$
\left\|\Theta\left(\xi_{\mathrm{j}}\right)-\Theta\left(\mathrm{v}_{\mathrm{i}}\right)\right\|^{2}=\mathrm{K}\left(\xi_{\mathrm{j}}, \xi_{\mathrm{j}}\right)-2 \mathrm{~K}\left(\xi_{\mathrm{j}}, \mathrm{v}_{\mathrm{i}}\right)+\mathrm{K}\left(\mathrm{v}_{\mathrm{i}}, \mathrm{v}_{\mathrm{i}}\right)
$$

By adopting the hyperbolic tangent function, $\mathrm{K}(\mathrm{x}, \mathrm{y})=1-\tanh \left(-\|\mathrm{x}-\mathrm{y}\|^{2} / \sigma^{2}\right)$, as a kernel function, we can define $\mathrm{d}(\mathrm{x}, \mathrm{y})$ as the following:

$$
\left.\mathrm{d}\left(\xi_{\mathrm{j}}, \mathrm{v}_{\mathrm{i}}\right) \square\left\|\Theta\left(\xi_{\mathrm{j}}\right)-\Theta\left(\mathrm{v}_{\mathrm{i}}\right)\right\|=\sqrt{2\left(1-\mathrm{k}\left(\xi_{\mathrm{j}}, \mathrm{v}_{\mathrm{i}}\right)\right.}\right)
$$

It's easy to prove that $\forall \mathrm{x} \neq \mathrm{y}, \mathrm{d}(\mathrm{x}, \mathrm{y})=\mathrm{d}(\mathrm{y}, \mathrm{x})>0$ and $\mathrm{d}(\mathrm{x}, \mathrm{x})=0$. Also we have: $\mathrm{d}(\mathrm{x}, \mathrm{y})=\|\Theta(\mathrm{x})-\Theta(\mathrm{y})\| \leq\|\Theta(\mathrm{x})-\Theta(\mathrm{z})\|+\|\Theta(\mathrm{z})-\Theta(\mathrm{y})\|=\mathrm{d}(\mathrm{x}, \mathrm{z})+\mathrm{d}(\mathrm{z}, \mathrm{y})$ Hence, $\mathrm{d}(\mathrm{x}, \mathrm{y})$ is a metric.

According to (10), (7) can be rewritten as follows:

$$
\mathrm{J}_{\mathrm{KFCM}}(\mathrm{U}, \mathrm{V})=\sum_{\mathrm{i}=1}^{2} \sum_{\mathrm{j}=1}^{\mathrm{n}} \mathrm{u}_{\mathrm{ij}}^{\mathrm{m}} \mathrm{d}\left(\xi_{\mathrm{j}}, \mathrm{v}_{\mathrm{i}}\right)^{2}
$$

\section{Integration strategy}

In this section the integration strategy is discussed. First, the Bayes classifier based on mixture of density models is utilized to find prior membership degrees of each pixel. Then, the novel supervised kernel-based fuzzy c-means clustering algorithm (SKFCM) is presented to implement approximated prior membership degrees. 


\subsection{Bayes classifier based on mixture of density models}

For every pixel $\xi$, we suppose that $\xi \in \mathrm{C}_{\mathrm{i}} \Leftrightarrow \mathrm{p}\left(\mathrm{C}_{\mathrm{i}} \mid \xi\right) \geq \mathrm{p}\left(\mathrm{C}_{\mathrm{j}} \mid \xi\right)$ where $\mathrm{C}_{1}=\{\xi \mid \varnothing(\mathrm{x}, \mathrm{y}) \geq 0\}$ and $\mathrm{C}_{2}=\Omega / \mathrm{C}_{1}$.

We can implement Bayes classifier based on mixture of density models [14] for finding the class-conditional densities. Therefore, $\mathrm{p}\left(\mathrm{C}_{\mathrm{i}} \mid \xi\right)$ can be calculated as follows:

$$
\mathrm{p}\left(\mathrm{C}_{\mathrm{i}} \mid \xi\right)=\sum_{\mathrm{i}=1}^{\mathrm{R}} \mathrm{p}\left(\mathrm{r}_{1} \mid \xi\right) \mathrm{P}\left(\mathrm{C}_{\mathrm{i}} \mid \mathrm{r}_{1}\right) \text { for } \mathrm{i}=1,2
$$

where $\mathrm{R}>2, \mathrm{p}\left(\mathrm{r}_{1} \mid \xi\right)$ and $\mathrm{P}\left(\mathrm{C}_{\mathrm{i}} \mid \mathrm{r}_{1}\right)$ denote the number of mixture models, the posteriori probability of $\xi$ derived from $\mathrm{r}_{1}$ th local model and the prior probability of this model represents the class $C_{i}$, respectively.

Based on the Bayesian rule, $p\left(r_{1} \mid \xi\right)$ can be written as follows:

$$
p\left(r_{i} \mid \xi\right)=\frac{p\left(\xi \mid r_{i}\right) P\left(r_{i}\right)}{\sum_{j=1}^{R} p\left(\xi \mid r_{j}\right) P\left(r_{j}\right)}
$$

Hence the posteriori class probability can be formulated as follows:

$$
\mathrm{p}\left(\mathrm{C}_{\mathrm{i}} \mid \xi\right)=\frac{\mathrm{p}\left(\xi \mid \mathrm{C}_{\mathrm{i}}\right) \mathrm{P}\left(\mathrm{C}_{\mathrm{i}}\right)}{\mathrm{P}(\xi)}=\sum_{\mathrm{i}=1}^{\mathrm{R}} \frac{\mathrm{p}\left(\xi \mid \mathrm{r}_{\mathrm{i}}\right) \mathrm{P}\left(\mathrm{r}_{\mathrm{i}}\right)}{\sum_{j=1}^{\mathrm{R}} \mathrm{p}\left(\xi \mid \mathrm{r}_{\mathrm{j}}\right) \mathrm{P}\left(\mathrm{r}_{\mathrm{j}}\right)} \mathrm{P}\left(\mathrm{C}_{\mathrm{i}} \mid \mathrm{r}_{1}\right)=\sum_{\mathrm{i}=1}^{\mathrm{R}} \frac{\mathrm{p}\left(\xi \mid \mathrm{r}_{1}\right) \mathrm{P}\left(\mathrm{r}_{\mathrm{i}}\right) \mathrm{P}\left(\mathrm{C}_{\mathrm{i}} \mid \mathrm{r}_{\mathrm{i}}\right)}{\mathrm{P}(\xi)}
$$

in which $\mathrm{p}\left(\xi \mid \mathrm{r}_{\mathrm{i}}\right)=\frac{1}{\left|2 \pi \mathrm{F}_{\mathrm{i}}\right|^{\frac{\mathrm{n}}{2}}} \exp \left(-\frac{1}{2}\left(\xi_{\mathrm{j}}-\mu_{\mathrm{i}}\right)^{\mathrm{T}} \mathrm{F}_{\mathrm{i}}^{-1}\left(\xi_{\mathrm{j}}-\mu_{\mathrm{i}}\right)\right)$

where $\mu_{\mathrm{i}}$ and $\mathrm{F}_{\mathrm{i}}$ represent the mean value and the covariance matrix of pixels in $r_{i}$, respectively.

\subsection{Supervised kernel-based fuzzy c-means clustering algorithm}

Prior membership degree given by (13) is denoted as $\boldsymbol{\kappa}_{\mathrm{ij}}$ and expressed as follows:

$$
\boldsymbol{N}=\left\{\left[\boldsymbol{N}_{\mathrm{ij}}\right]_{\mathrm{j}=1, \ldots, \mathrm{n}} \mid \boldsymbol{N}_{\mathrm{ij}}=\mathrm{p}\left(\mathrm{C}_{\mathrm{i}} \boldsymbol{\xi}_{\mathrm{j}}\right)\right\}
$$

To improve the performance of KFCM, we incorporate $\boldsymbol{N}$, as a component of supervised learning, into modified KFCM objective function as follows:

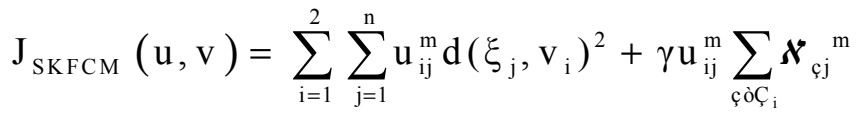

in which $C_{i}=\{\{1,2\}, \quad i\}$ and $\gamma$ is a control parameter which keeps a balance between the original KFCM and CV method in the optimization procedure. 
To find the optimal values of $v_{i}$ and $u_{i j}$ considering the constraint (6), we introduce a Lagrange multiplier $l$ and minimize the following Lagrange function $\mathrm{L}$ :

$\mathrm{L}(\mathrm{U}, \mathrm{V}, \mathrm{l})=\sum_{\mathrm{i}=1}^{2} \sum_{\mathrm{j}=1}^{\mathrm{n}} \mathrm{u}_{\mathrm{ij}}^{\mathrm{m}} \mathrm{d}(\mathrm{x}, \mathrm{y})^{2}+\gamma \mathrm{u}_{\mathrm{ij}}^{\mathrm{m}} \sum_{\mathrm{c} \dot{\mathrm{o}} \zeta_{\mathrm{i}}} \boldsymbol{N}_{\mathrm{c}, \mathrm{j}}^{\mathrm{m}}-l\left(\sum_{\mathrm{i}=1}^{\eta} \mathrm{u}_{\mathrm{ij}}-1\right)$

Assume that $u_{k j}$ is the membership degree of $\xi_{j}$ belonging to the cluster $\eta_{k}$ whose centroid is $\mathrm{V}_{\mathrm{k}}$. The stationary point of the optimized functional can be obtained as $\left(\mathrm{u}_{\mathrm{kj}}, \mathrm{v}_{\mathrm{k}}, l\right)$ if and only if $\frac{\partial \mathrm{L}}{\partial \mathrm{l}}=0, \frac{\partial \mathrm{L}}{\partial \mathrm{v}_{\mathrm{k}}}=0$ and $\frac{\partial \mathrm{L}}{\partial \mathrm{u}_{\mathrm{kj}}}=0$.

Taking these derivatives returns the relationships as follows:

$$
\frac{\partial \mathrm{L}}{\partial l}=\sum_{\mathrm{i}=1}^{2} \mathrm{u}_{\mathrm{kj}}-1=0
$$

The optimal solution for $\mathrm{V}_{\mathrm{k}}$ is given as follows:

$$
\mathrm{v}_{\mathrm{k}}=\frac{\sum_{\mathrm{j}=1}^{\mathrm{n}} \mathrm{u}_{\mathrm{kj}}^{\mathrm{m}}\left(1-\left(\mathrm{K}\left(\xi_{\mathrm{j}}, \mathrm{v}_{\mathrm{k}}\right)-1\right)^{2}\right) \xi_{\mathrm{j}}}{\sum_{\mathrm{j}=1}^{\mathrm{n}} \mathrm{u}_{\mathrm{kj}}^{\mathrm{m}}\left(1-\left(\mathrm{K}\left(\xi_{\mathrm{j}}, \mathrm{v}_{\mathrm{k}}\right)-1\right)^{2}\right)}
$$

Similarly, we take the derivative of $\mathrm{L}\left(\mathrm{u}_{\mathrm{kj}}\right)$ with respect to $\mathrm{u}_{\mathrm{ij}}$ and fixed it to zero:

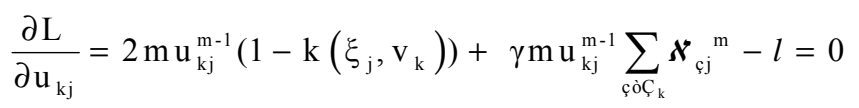

thus

$$
2 \mathrm{mu}_{\mathrm{kj}}^{\mathrm{m}-1}\left(1-\mathrm{k}\left(\xi_{\mathrm{j}}, \mathrm{v}_{\mathrm{k}}\right)\right)+\gamma \mathrm{mu} \mathrm{kj}_{\mathrm{kj}}^{\mathrm{m}-1} \sum_{\mathrm{c}_{\mathrm{o}} \mathrm{c}_{\mathrm{k}}} \boldsymbol{N}_{\mathrm{c} \mathrm{j}}^{\mathrm{m}}=l
$$

We set $m=2$, thus

$$
\mathrm{u}_{\mathrm{kj}}=\left(\frac{l}{2\left(2\left(1-\mathrm{k}\left(\xi_{\mathrm{j}}, \mathrm{v}_{\mathrm{k}}\right)\right)+\gamma \sum_{\mathrm{cò}_{\mathrm{k}}} \boldsymbol{N}_{\mathrm{cj}}^{2}\right)}\right)
$$

$\mathrm{u}_{\mathrm{kj}} \in \mathrm{M}$ indicates that

$$
1=\frac{l}{2} \sum_{\mathrm{i}=1}^{2}\left(\frac{1}{\left(2\left(1-\mathrm{k}\left(\xi_{\mathrm{j}}, \mathrm{v}_{\mathrm{k}}\right)\right)+\gamma \sum_{\mathrm{c}_{\mathrm{o}} \mathrm{C}_{\mathrm{i}}} \boldsymbol{N}_{\mathrm{cj}}^{2}\right)}\right)
$$

Hence 


$$
l=\frac{2}{\sum_{\mathrm{i}=1}^{2}\left(\frac{1}{\left(2\left(1-\mathrm{k}\left(\xi_{\mathrm{j}}, \mathrm{v}_{\mathrm{k}}\right)\right)+\gamma \sum_{\varphi \dot{\varphi} \mathcal{C}_{i}} \boldsymbol{N}_{\mathrm{cj}}{ }^{2}\right)}\right)}
$$

Therefore, the optimal solution of $\mathrm{u}_{\mathrm{kj}}$ is formulated as follows:

$$
\mathrm{u}_{\mathrm{kj}}=\frac{1}{\sum_{\mathrm{i}=1}^{2}\left(\frac{\left(2\left(1-\mathrm{k}\left(\xi_{\mathrm{j}}, \mathrm{v}_{\mathrm{k}}\right)\right)+\gamma \sum_{\mathrm{co} \mathrm{c}_{\mathrm{k}}} \boldsymbol{k}_{\mathrm{cj}}^{2}\right)}{\left(2\left(1-\mathrm{k}\left(\xi_{\mathrm{j}}, \mathrm{v}_{\mathrm{i}}\right)\right)+\gamma \sum_{\mathrm{c} \dot{c}_{\mathrm{i}}} \boldsymbol{N}_{\mathrm{cj}}^{2}\right)}\right)}
$$

\section{Experimental results}

We tested our algorithm on the human HT29 colon cancer cells with a size of $512 \mathrm{x}$ 512 pixels from image set BBBC008v1 $[15,16]$ which were stained cell nuclei and have ground truth to show the segmentation performance of the proposed technique. An example of original image, ground truth and segmentation result based on the proposed method are shown in Fig. 1. The proposed method is compared with FCM, CV, SFCM [17], SFLS [18] and region-scalable fitting energy (RSFE) [19]. To evaluate the performance of our algorithm, we calculate the recognition error rate as follows:

$$
\text { recognition error rate }(\%)=\frac{T_{\text {cell }}+T_{\text {background }}}{n} \times 100
$$

where $\mathrm{n}$ indicates the total number of pixels in the given image, $\mathrm{T}_{\text {cell }}$ and $\mathrm{T}_{\text {background }}$ are the number of pixels incorrectly classified as the cell and background, respectively.

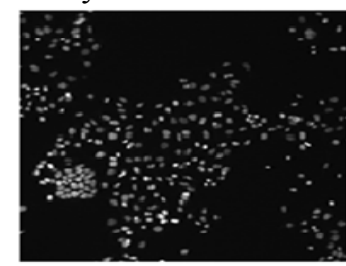

(a)

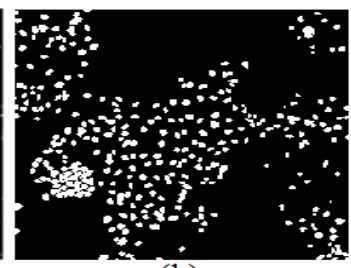

(b)

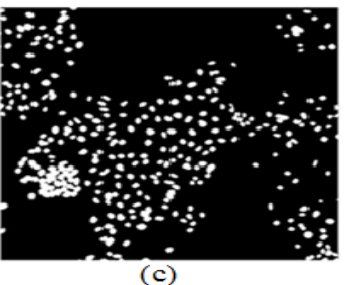

(c)

Fig.1. Example of (a) Original image, (b) Ground truth and (c) Segmentation result 
Table1. Recognition error rate for different segmentation methods

\begin{tabular}{|c|c|c|c|c|c|c|c|c|c|c|c|c|}
\hline \multicolumn{6}{|c|}{ human HT29 colon cancer cells } & \multicolumn{7}{|c|}{ " human HT29 colon cancer cells with 5\% Gaussian noise } \\
\hline $\begin{array}{l}\text { Image } \\
\text { index }\end{array}$ & $\begin{array}{l}\text { FCM } \\
\end{array}$ & $\begin{array}{ll}\mathrm{CV} \\
\end{array}$ & $\begin{array}{l}\mathrm{SFC} \\
\mathrm{M}\end{array}$ & $\begin{array}{l}\text { RSFE } \\
\end{array}$ & $\begin{array}{l}\text { SFLS } \\
\end{array}$ & $\begin{array}{l}\text { Proposed } \\
\text { Method } \\
\text { (SKFCM) }\end{array}$ & FCM & $\overline{C V}$ & 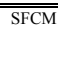 & RSFE & SFLS & $\begin{array}{l}\text { Proposed } \\
\text { Method } \\
\text { (SKFCM) }\end{array}$ \\
\hline 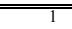 & $\bar{~} 2.43$ & 40.03 & $\bar{~} \overline{3.2}$ & 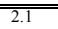 & 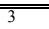 & $\begin{array}{ll}1.07 \\
\end{array}$ & 4.68 & "5.03 & $\overline{40.2}$ & (3.68 & " & $\begin{array}{l}2.07 \\
\end{array}$ \\
\hline 2 & 2.39 & 3.21 & 3.34 & 2.02 & 3.07 & 2.01 & 5.39 & 4.53 & 4.14 & 3.92 & 3.87 & 2.91 \\
\hline 3 & 1.64 & 3.12 & 2.17 & 1.41 & 2.05 & 0.91 & 4.64 & 3.52 & 3.07 & 3.21 & 3.15 & 2.66 \\
\hline 4 & 0.94 & 1.08 & 1.55 & 1.05 & 1.41 & 0.57 & 1.94 & 2.08 & 1.75 & 1.82 & 1.71 & 1.29 \\
\hline 5 & 3.2 & 5.56 & 7.6 & 3.01 & 8.34 & 2.31 & 7.54 & 7.71 & 6.86 & 4.32 & 7.34 & 3.77 \\
\hline 6 & 5.37 & 3.055 & 3.32 & 2.89 & 3.04 & 1.78 & 6.46 & 4.53 & 5.17 & 3.94 & 4.12 & 2.79 \\
\hline 7 & 1.63 & 2.01 & 2.23 & 2.22 & 2.07 & 1.14 & 2.91 & 3.04 & 2.65 & 2.39 & 2.53 & 1.97 \\
\hline 8 & 1.16 & 1.45 & 1.7 & 1.57 & 1.71 & 0.67 & 1.92 & 1.85 & 1.77 & 1.87 & 1.8 & 1.07 \\
\hline 9 & 1.19 & 1.39 & 1.59 & 1.4 & 1.5 & 0.81 & 2.38 & 1.99 & 1.83 & 1.8 & 1.81 & 1.31 \\
\hline 10 & 5.6 & 2.18 & 2.24 & 2.17 & 2.24 & 1.17 & 5.6 & 4.89 & 4.91 & 4.7 & 4.81 & 2.76 \\
\hline 11 & 1.15 & 1.23 & 1.33 & 1.18 & 1.33 & 0.49 & 3.13 & 2.8 & 2.54 & 2.42 & 2.51 & 1.69 \\
\hline 12 & 1.47 & 1.5 & 1.77 & 1.45 & 1.79 & 1.41 & 2.5 & 2.29 & 2.47 & 2.55 & 2.33 & 2.19 \\
\hline
\end{tabular}

The recognition error rates for both normal and noisy image are reported in Table1. Fig. 3 also shows the segmentation results (error rate) based on the different segmentation methods and noise levels. In order to evaluate the robustness of the various methods on BBBC008v1, we plot the standard deviation. Fig. 2 shows the standard deviation (error bar) of the compared approaches. As can be seen in Fig. 2 the proposed algorithm has better average segmentation accuracy and small standard error compared to the five other existing algorithms.

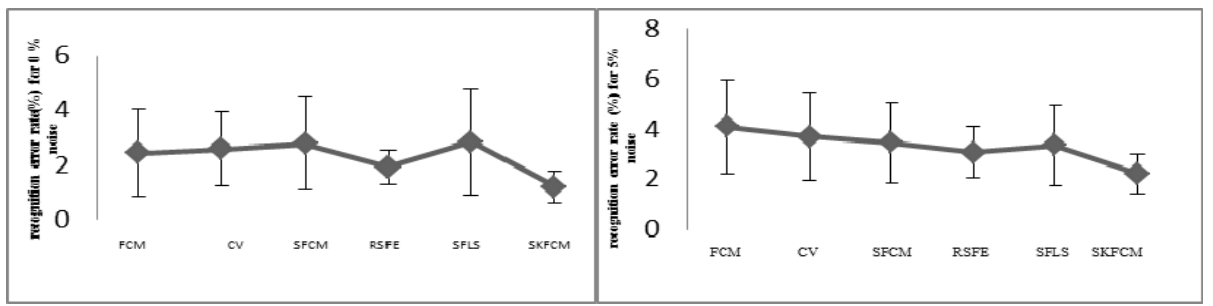

Fig.2. The standard deviation (error bar) of the various methods on BBBC008v1 


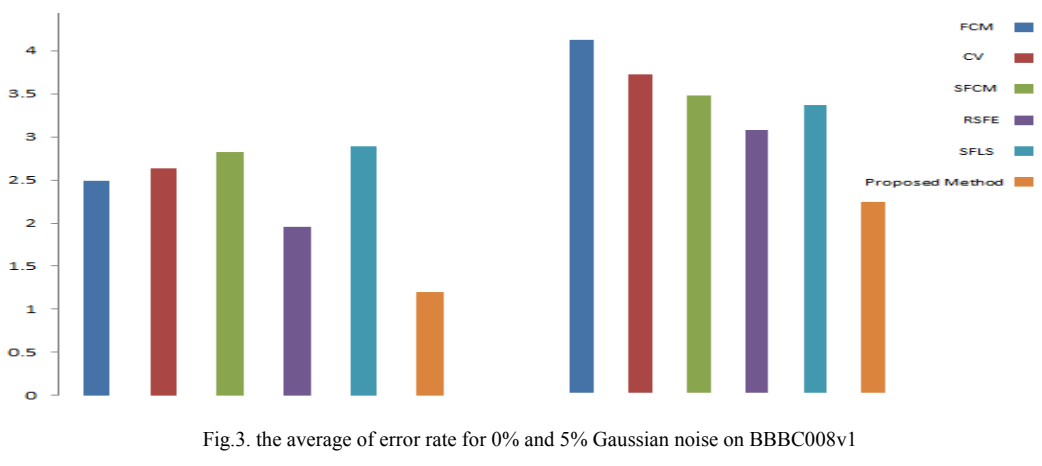

\section{Conclusion}

In this study, we proposed an image segmentation algorithm based on combining $\mathrm{KFCM}$ and $\mathrm{CV}$ for the segmentation of the colon cancer cells images. We compared the results of our algorithm with the results of FCM, CV, SFCM, SFLS and RSFE, and show that our algorithm performed significantly better than these methods in terms of segmentation accuracy.

There are two critical issues related to our method. One is the selection of suitable kernel for the specific image. In practice, the performance of kernel-based methods is influenced by the selection of the kernel function. While solutions for estimating the optimal kernel function for supervised tasks can be found in the literatures, the challenge remains an open problem for unsupervised tasks. Secondly, a potential drawback of the Bayes classifier used in the integration process is that for each $C_{i}$ many characteristics of the class are considered which may not be useful to differentiate the classes.

\section{Acknowledgement}

This work was supported by the Australian Research Council (ARC) Discovery Grant DP1097059 and the Griffith International Postgraduate Research Scholarship (GUIPRS).

\section{References}

1. S. Osher and J. A. Sethian, "Fronts propagating with curvature-dependent speed: Algorithms based on Hamilton-Jacobi Formulation," Journal of Computational Physics, vol. 79, pp. 12-49, 1988.

2. R. Malladi, J. A. Sethian, and B. C. Vemuri, "Shape modeling with front propagation: A level set approach,'IEEE Transaction on Pattern Analysis and Machine Intelligence, vol. 17 , no. 2 , pp. $158-175,1995$.

3. T.F. Chan and L.A. Vese, "Active Contours without edges," IEEE transactions on Image Processing, vol. 10, no.2, pp.266-277, 2001. 
4. J. Dunn, "A fuzzy relative of the ISODATA process and its use in detecting compact, wellseparated clusters," Journal of Cybernetics, vol. 3, no. 3, pp. 32-57, 1973.

5. J. Bezdek, Pattern recognition with fuzzy objective function algorithms, Plenum Press, New York, 1981.

6. A.W.C. Liew, S.H. Leung, W.H. Lau, "Fuzzy image clustering incorporating spatial continuity", IEE Proceedings-Vision Image and Signal Processing, 147(2):185-192, 2000.

7. A.W.C. Liew, H. Yan, "An adaptive spatial fuzzy clustering algorithm for 3-D MR image segmentation", IEEE Transactions on Medical Imaging, 22(9): 1063-1075, Sep 2003.

8. A.W.C. Liew; S.H. Leung, W.H. Lau, "Segmentation of color lip images by spatial fuzzy clustering", IEEE Transactions on Fuzzy Systems, 11(4): 542-549, Aug 2003

9. M. Girolami, "Mercer kernel-based clustering in feature space", IEEE Transactions on Neural Network. 13(3), pp.780-784, 2002.D.

10. Mumford and J. Shah, "Optimal approximation by piecewise smooth functions and associated variational problems," Communications on Pure and Applied Mathematics, vol. 42, pp. 577-685, 1989.

11. J. M. Morel and S. Solimini, "Segmentation of Images by Variational Methods: A Constructive Approach", Madrid, Spain: Revista Matematica Universidad Complutense de Madrid, vol. 1, pp. 169-182, 1988.

12. N.R. Pal, K. Pal, J. M. Keller, J. Bezdek, "A possibilistic fuzzy c-means clustering algorithm," IEEE Transactions on Fuzzy Systems, vol. 13, no. 4, pp. 517-530, 2005.

13. F. Höppner and F. Klawonn, "A contribution to convergence theory of fuzzy c-means and derivatives," IEEE Transactions on Fuzzy Systems, vol. 11, no. 5, pp. 682-694, Oct. 2003.

14. J. Abonyi, F.Szeifert. "Supervised fuzzy clustering for the identification of fuzzy classifiers," Pattern Recognition Letters. 24, pp. 2195-2207, 2003.

15. www.broadinstitute.org/bbbc

16. A.E. Carpenter, T.R. Jones, M.R. Lamprecht, C. Clarke, IH. Kang, O. Friman, DA. Guertin, JH. Chang, RA. Lindquist, J. Moffat, P. Golland, DM. Sabatini, "CellProfiler: image analysis software for identifying and quantifying cell phenotypes," Genome Biology, 7:R100, 2006.

17. K.S. Chuang, H.L. Hzeng, S. Chen, J. Wu, T.J. Chen, 'Fuzzy c-means clustering with spatial information for image segmentation," Computerized Medical Imaging and Graphics, vol.30, pp. 9-156, 2000.

18. Li, B. N., Chui, C. K., Chang, S., \& Ong, S. H., "Integrating spatial fuzzy clustering and level set methods for automated medical image segmentation," Computers in Biology and Medicine, vol. 41, pp.1-10, 2011.

19. Li, C., Kao, C., Gore, J., Ding, Z., "Minimization of region-scalable fitting energy for image segmentation," IEEE Transactions on Image Processing, vol.17, pp.1940-1949, 2008. 